\title{
Desigualdade da renda e as "aposentadorias e pensões" no Brasil, na Região Sul e no Estado do Paraná
}

\section{Inequality of the income and the 'retirements and pension' in Brazil, southern region and State of Paraná}

\author{
Carlos Roberto Ferreira ${ }^{1}$; Solange de Cássia Inforzato de Souza ${ }^{2}$
}

\begin{abstract}
Resumo
Este trabalho tem como objetivo avaliar a contribuição do componente do rendimento domiciliar "aposentadorias e pensões" para a desigualdade da distribuição do rendimento domiciliar per capita no Brasil, Região Sul e Estado do Paraná, nos meios rural e urbano, em 1999, 2001 e 2002. Para isso, utilizou-se a estratificação do rendimento domiciliar per capita e a metodologia de decomposição do índice de Gini dos seguintes componentes: rendimento do trabalho principal, rendimento de outros trabalhos, aposentadorias e pensões, doações, rendimentos de aluguel e outros rendimentos (juros, dividendos, etc.). Salienta-se, nos resultados, a substancial contribuição das aposentadorias e pensões para a desigualdade da distribuição da renda no Brasil e na região sul. Na Região Sul rural e Paraná rural essa situação não se efetiva, com exceção do ano de 2002, contrariando a tendência brasileira. A estratificação dos rendimentos domiciliares permitiu a verificação de que, para todas as regiões rurais analisadas, há uma melhor distribuição dos rendimentos das aposentadorias e pensões localizados nos estratos inferiores da renda.

Palavras-chave: Previdência social. Aposentadorias e pensões. Distribuição de renda.
\end{abstract}

\begin{abstract}
The purpose of this work is to evaluate the component of the household revenue "retirements and pensions" contribution for the inequality of the household revenue distribution per capita in Brazil, southern region and State of Paraná, in the rural and urban environments, in 1999, 2001 and 2002. As for this, the household revenue per capita and the decomposition methodology of Gini's index of the following components were used: revenue of the main work, revenue of other works, retirements and pensions, donations, rent revenues and other revenues (interests, dividends, etc.). It is highlighted in the results, the substantial contribution of the retirements and pensions for the inequality of the income distribution in Brazil and in the southern region. In the rural southern region and rural Paraná that situation does not happen, except for the year 2002, refuting the Brazilian tendency. The stratification of the household revenues enabled us to verify that, for all the analyzed rural areas, there is a better distribution of the revenues of retirements and pensions located in the inferior strata of the income.
\end{abstract}

Key words: Social welfare. Retirements and pensions. Distribution of income.

\footnotetext{
${ }^{1}$ Professor Adjunto da Universidade Estadual de Londrina, Londrina-Pr. E-mail: robert@uel.br.

${ }^{2}$ Professora Adjunta da Universidade Estadual de Londrina, Londrina-Pr. E-mail: soinfor@uel.br
} 


\section{Introdução}

As transformações manifestadas no perfil demográfico da população e no mercado de trabalho levaram a constrangimentos nas contas da Previdência Social e fizeram com que, a partir de meados da década de noventa do século XX, fosse intensificado o debate acerca dessa instituição. As informações são as de que, no ano de 2002, o país tinha 16.022.231 pessoas com mais de 60 anos, 9,3\% da população. Desse montante, 12.445.563 eram aposentados ou pensionistas, ou seja, 77,7\% do total de idosos. (INSTITUTO BRASILEIRO DE GEOGRAFIA E ESTATÍSTICA, 2003)

Demograficamente, a população mundial e brasileira tem apresentado baixas taxas de fecundidade, aumento da longevidade e urbanização acelerada, e a interação desses fatores resulta em um maior crescimento da população idosa em relação aos demais grupos. A pesquisa de Camarano (2002) mostra que a participação da população maior de 60 anos na população brasileira mais do que dobrou no último meio século, passando de 4\% em 1940 para $8 \%$ em 1996. A autora estima que em 2020 aproximadamente $15 \%$ da população será composta por idosos.

Os impactos da dinâmica demográfica com respeito à Previdência Social refletem-se tanto nas despesas com benefícios, quanto no lado das receitas. Para manter o equilíbrio no sistema de repartição simples, o elemento fundamental, considerando-se somente as variáveis demográficas, é a estrutura etária da população em cada momento, pois é ela que define a relação entre beneficiários e contribuintes.(STEPHANES, 1999)

Segundo Stephanes (1999), a relação de contribuintes ativos por beneficiário na década de 1950 era de oito, enquanto para as décadas de 1970 e 1980 essa relação foi de 4,2 e 3,2, respectivamente. Para Ornélas (2002), essa mesma relação caiu de 2,4 em 1991 para 1,7 em 1997. Essa queda implicou sucessivos aumentos das alíquotas de contribuição, redução no valor real dos benefícios e utilização de receita de impostos para cobrir o déficit da
Previdência Social. E mais, Ornélas e Vieira (2002) salientam que a base de contribuintes da previdência no Brasil esteve sempre abaixo do seu potencial. Em 1997 , cerca de $62 \%$ da população ocupada não contribuía para o Regime Geral de Previdência Social (RGPS) e 56\% não contribuía para nenhum tipo de previdência.

Com relação à composição do mercado formal, Najberg e Ikeda (1999) observam uma tendência de redução da participação de salários no total de produção, especialmente no setor industrial, no qual essa participação é mais expressiva. O setor industrial tem perdido posição em favor do setor de comércio e de serviços, que empregam cada vez mais trabalhadores, mas com elevado grau de informalidade. Além disso, verifica-se uma tendência de remunerar o trabalhador formal com menor salário e com participação nos lucros através de gratificação, bônus ou dividendos, sem que haja incidência de contribuição, tanto do empregado, quanto do empregador. Essas novas tendências contribuem para intensificar a problemática da Previdência Social no Brasil.

Por outro lado, o efeito distributivo dos gastos sociais é reduzido, sendo seu perfil desfavorável mesmo aos contingentes mais pobres da população. Estimativas do Banco Mundial, referentes a 1990, indicam que o valor per capita dos gastos sociais, sem incluir os benefícios pagos pela Previdência, relativos aos $20 \%$ mais pobres da população, era $13 \%$ inferior à cifra correspondente aos $80 \%$ restantes. Esse diferencial aumenta quando se consideram os benefícios pagos pela Previdência. O valor per capita dos gastos sociais referentes aos $20 \%$ mais pobres era $40 \%$ menor do que o valor relativo aos outros $80 \%$ da população. Esses dados mostram que, quando se consideram os benefícios pagos pela Previdência, o perfil da distribuição é ainda mais desfavorável aos segmentos mais pobres. IPEA (1996)

A literatura econômica mostra que os gastos com aposentadorias e pensões em geral são distribuídos de forma inadequada, quando considerados como gastos sociais destinados a combater a pobreza. Neste 
aspecto, trabalhos como os de Ferreira e Souza (2004a), Ferreira e Souza (2004b), Ferreira (2003), Amsberg, Lanjouw e Nead (2000) e Barros e Foguel (2000), entre outros, retratam essa situação para o país.

Diante disso, este artigo tem como objetivo principal medir e analisar a contribuição das aposentadorias e pensões na desigualdade da distribuição do rendimento domiciliar per capita no Brasil, Região Sul e Paraná, nos meios urbano e rural, nos anos de 1999, 2001 e 2002. A mensuração foi efetuada por meio da estratificação do rendimento domiciliar per capita e da decomposição do índice de Gini.

$O$ trabalho segue com os antecedentes da previdência social rural no Brasil, e, nas seções 3 e 4, explicitando a base de dados e a metodologia aplicada. Na seção 5, discute-se a concentração da renda domiciliar per capita por diferentes estratos e decompõe o índice de Gini, avaliando a magnitude da contribuição dos componentes do rendimento domiciliar per capita no Brasil, na Região Sul e no Estado do Paraná. Ao final, as conclusões são apresentadas.

\section{Previdência Social e sua Expressão Rural no Brasil: os antecedentes}

A dificuldade de sustentação do sistema de proteção social do Brasil eleva-se a partir da aprovação da Constituição de 1988, cujos impactos no Regime Geral de Previdência Social e no Regime de Servidores Públicos são percebidos.

No tocante à população rural, os benefícios previdenciários tornam-se mais visíveis em resposta ao conteúdo favorável da Constituição de 1988 para a seguridade social dos idosos do meio rural. Com isso, aumentaram expressivamente a quantidade de benefícios e o seu valor médio, principalmente para os benefícios rurais, que passaram de meio para um salário mínimo. De acordo com Delgado e Cardoso Júnior (2002), a previdência rural pagou, em 1998, 6,91 milhões de aposentadorias, pensões, rendas mensais vitalícias e amparos previdenciários aos seus segurados. Conforme Brant (2001a), entre 1988 e
2000, o número de benefícios pagos pelo sistema aumentou 71,6\%, passando de 11,6 milhões em 1988 para 19,9 milhões em 2000. O aumento da quantidade e do valor médio dos benefícios fez com que a despesa com benefícios pagos pela previdência mais do que duplicasse, passando de 2,6\% do PIB em 1988 para $6,1 \%$ em 2000.

Institucionalmente, a previdência social brasileira, que teve seu marco legal estabelecido pela lei Eloy Chaves, em 1923, pôde constituir sua face rural a partir da criação do Funrural (Fundo de Assistência e Previdência do Trabalhador Rural), em 1963, como parte do Estatuto do Trabalhador Rural. Os esforços anteriores para a proteção social dos trabalhadores rurais podem ser resumidos na criação do Instituto de Serviços Sociais do Brasil (ISSP), de 1945, que não chegou a ser implementado, e do Serviço Social Rural, em 1955.

Da origem do Funrural até a sua extinção, em 1977, iniciativas governamentais foram tomadas no campo da previdência social rural, com a finalidade de prover o amparo previdenciário a trabalhadores e empregadores rurais, por meio da assistência médica e social e benefícios financeiros. Essas medidas também visavam a organizar a estrutura administrativa e financeira por meio do Funrural e do Instituto Nacional de Previdência Social (INPS).

Os anos imediatamente após 1977 vão representar para a Previdência Social, sob um sistema único, o início de uma universalização da seguridade social no Brasil, ainda que com planos de benefícios distintos para trabalhadores urbanos e rurais. O Sinpas (Sistema Nacional de Previdência e Assistência Social), inaugurado em 1977, foi a materialização da unidade do sistema previdenciário. A obtenção do benefício rural de aposentadoria atingia o cabeça do casal, aos 65 anos de idade, com valores de meio a 3/4 do salário mínimo.

Todavia, a Constituição Federal de 1988, em seu artigo 194, veio instituir a "uniformidade e equivalência dos benefícios e serviços às populações urbanas e rurais", regulamentadas a partir de 1992, dando igualdade de acesso a homens e mulheres com idade de 60 anos(homens) e 55 anos(mulheres), com 
benefícios de aposentadorias e pensões de um salário mínimo. Em seu parágrafo oitavo, cita-se o produtor, parceiro, meeiro e arrendatário rurais e seus cônjuges, cujas atividades se enquadram no regime de economia familiar, sem empregados permanentes.

Se se adiciona aos produtores em regime de economia familiar o trabalhador rural formal protegido socialmente, percebe-se a relevância da Previdência Social Rural, realizada com a ampliação da cobertura do sistema e o incremento da renda familiar. Daí que, no contexto de sobrevivência econômica das famílias no meio rural, o idoso rural tem seu papel econômico e social transformado: de assistidos para assistentes da família.(DELGADO; CARDOSO JÚNIOR, 1999).

\section{Base de Dados}

$\mathrm{O}$ presente estudo tem por base as informações coletadas na Pesquisa Nacional por Amostra de Domicílios (PNAD), em 1999, 2001 e 2002. A PNAD tem sido realizada anualmente desde 1971 e é interrompida por ocasião dos Censos Demográficos (1970, 1980, 1991 e 2000). Trata-se de um levantamento anual realizado por meio de uma amostra dos domicílios que abrange todo o país, exceto a área rural de quase todos os Estados da Região Norte (Acre, Amapá, Amazonas, Pará, Rondônia e Roraima). Para as pesquisas da década de 90, essa abrangência geográfica foi mantida, ou seja, a PNAD continuou a cobrir todo o país, com exceção da área rural dessas seis unidades da Federação.

O procedimento metodológico adotado pelo IBGE implica que cada pessoa da amostra representa um determinado número de pessoas da população. Os dados individuais são fornecidos com o peso ou fator de expansão de cada indivíduo. Isso permite que os cálculos sejam elaborados, ponderando-se cada observação pelo respectivo peso. Todos os cálculos, neste trabalho, foram feitos considerando o peso ou fator de expansão de cada domicílio da amostra da PNAD, fornecido pelo IBGE.
As informações das PNADs são de boa qualidade, mas é preciso observar algumas características da natureza desses dados, as quais são restrições que precisam ser levadas em consideração na análise dos resultados, conforme alerta Hoffmann (1988) e Hoffmann (2002).

De acordo com as notas metodológicas do Instituto Brasileiro de Geografia e Estatística (2001), "considerou-se como rendimento mensal domiciliar a soma dos rendimentos mensais dos moradores do domicílio, exclusive os das pessoas cuja condição no domicílio fosse pensionista, empregado doméstico ou parente do empregado doméstico". Para se obter o rendimento domiciliar per capita, dividiu-se o rendimento mensal domiciliar pelo número de pessoas do domicílio, excluindo pensionistas, empregados domésticos e seus parentes.

Os componentes do rendimento domiciliar são os provenientes do trabalho principal, de outros trabalhos, de aposentadorias e pensões, dos aluguéis, doações, juros, etc., apresentados para as pessoas de dez anos ou mais de idade. Consideram-se rendimentos de trabalho os decorrentes dos pagamentos brutos mensais aos empregados, empregadores e conta própria, sejam advindos do trabalho principal ou dos demais trabalhos. O trabalho principal é o único trabalho que a pessoa teve no período da pesquisa (semana de referência da PNAD), impondo-se outros critérios para casos especiais.

Os rendimentos de aposentadorias e pensões são aqueles pagos pelo Governo Federal ou por instituto de previdência, entidades seguradoras ou fundos de pensão; e finalmente, juros, etc.Esses rendimentos são decorrentes de aplicações financeiras em ativos financeiros de renda fixa, caderneta de poupança, e outros. (INSTITUTO BRASILEIRO DE GEOGRAFIA E ESTATÍSTICA, 2001).

\section{Metodologia da Pesquisa}

Os procedimentos da pesquisa contemplaram a estratificação do rendimento domiciliar per capita e a decomposição do índice de Gini. Tais procedimentos foram realizados, inicialmente, para o Brasil e a 
Região Sul, e permitiram uma contextualização referente ao Estado do Paraná, no qual foram salientadas as diferenças entre os meios urbano e rural.

Para a estratificação do rendimento domiciliar per capita, consideram-se 11 estratos de renda, ressaltando-se que, para todo o período analisado, foram construídas tabelas que mostram a distribuição dos domicílios, do rendimento total, e do rendimento domiciliar de aposentadorias e pensões.

O primeiro estrato inclui os domicílios cujo rendimento declarado é igual a zero. O segundo inclui os domicílios cujo rendimento declarado é igual até meio salário mínimo corrente ${ }^{3}(\mathrm{SM})$; o terceiro inclui rendimento entre meio SM e um SM; o quarto inclui rendimento entre um SM e um e meio SM; o quinto inclui rendimento entre um e meio SM e dois SM; o sexto inclui rendimento entre dois $\mathrm{SM}$ e dois e meio $\mathrm{SM}$; o sétimo inclui rendimento entre dois e meio SM e três SM; o oitavo inclui rendimento entre três $\mathrm{SM} \mathrm{e}$ quatro SM; o nono inclui rendimento entre quatro e oito SM; o décimo inclui rendimento entre oito e quinze $\mathrm{SM}$; e o décimo primeiro inclui rendimentos maiores que quinze SM. Ressalte-se que os domicílios com rendimentos não-declarados foram eliminados da análise.

$\mathrm{Na}$ decomposição do índice de Gini, o texto de Pyatt, Chen e Fei (1980) mostra de forma clara como o índice de Gini pode ser decomposto quando se considera a divisão do rendimento analisado em vários componentes ${ }^{4}$.

Seja $z_{i}$ o rendimento da i-ésima pessoa. Neste trabalho, considera-se o rendimento domiciliar per capita, considerando que ele é o resultado da soma de k parcelas:

$$
z_{i}=\sum_{h=1}^{k} z_{h i}
$$

Vamos admitir que os rendimentos $z_{i}$ estão ordenados de maneira que $z_{1} \leq z_{2} \leq \ldots \leq z_{n}$, sendo n o tamanho da população. Então i é a posição de ordem do rendimento $z_{i}$.
Pode-se verificar que o índice de Gini (G) da distribuição de $z_{i}$ é

$$
\begin{aligned}
& G=\frac{2}{n \mu} \operatorname{cov}\left(z_{i}, i\right) \\
& \text { onde } \mu \text { é a média dos } z_{i} .
\end{aligned}
$$

Pyatt, Chen e Fei (1980) definem a razão de concentração do componente $z_{h i}$ como

$$
C_{h}=\frac{2}{n \mu_{h}} \operatorname{cov}\left(z_{h i}, i\right)
$$

onde $\mu_{h}$ é a média dos $z_{h i}$.

A participação do $h$-ésimo componente no rendimento total é

$$
\phi_{h}=\frac{\mu_{h}}{\mu}
$$

Pode-se deduzir que

$G=\sum_{h=1}^{k} \phi_{h} C_{h}$

Vamos indicar por $i_{h}$ os números de ordem associados aos valores de $z_{h i}$, como se eles fossem colocados em ordem crescente. Os $i_{h}$, da mesma maneira que $i$, variam de 1 a $n$. Note-se, entretanto, que, para determinar $z_{h i}$, o respectivo valor de $i$ ( o número de ordem do correspondente $z_{i}$ ) não vai, em geral, coincidir com $i_{h}$ (a posição desse $z_{h i}$ na ordenação dos valores desse componente). Analogamente a (2), o índice de Gini de $z_{h i}$ é:

$G_{h}=\frac{2}{n \mu_{h}} \operatorname{cov}\left(z_{h i}, i_{h}\right)$

De (3) e (6) obtém-se:

$$
R_{h}=\frac{C_{h}}{G_{h}}=\frac{\operatorname{cov}\left(z_{h i}, i\right)}{\operatorname{cov}\left(z_{h i}, i_{h}\right)}
$$

\footnotetext{
${ }_{3}^{3}$ Em termos nominais, o valor do salário mínimo em 1999, 2001 e 2002 foi de $\mathrm{R} \$ 136,00 ; \mathrm{R} \$ 180,00$ e R \$ 200,00 respectivamente

${ }^{4}$ Ver, também, Shorrocks (1982). No Brasil essa metodologia já foi utilizada por Ferreira (2003), Neder (2001) e Mariano e Lima (1998).
} 
Pyatt, Chen e Fei (1980) denominaram $R_{h}$ de "razão de correlação de ordem", ressaltando que ela não constitui um coeficiente de correlação de ordem. Eles mostram que

$R_{h} \leq 1$

De (5) e (7) segue-se que

$G=\sum_{h=1}^{k} \phi_{h} R_{h} G_{h}$

Essa expressão mostra como o índice de Gini de $z_{i}$ está associado com os índices de Gini de cada componente.

Note-se, na expressão (5), que se todas as razões de concentração $C_{h}$ tivessem o mesmo valor, esse seria, também, o valor de $G$. Dessa forma, pode-se considerar que um componente $z_{h i}$ contribui para aumentar a desigualdade (medida pelo índice de Gini) quando $C_{h}>G$.
Essa expressão mostra como o índice de Gini de $z_{i}$ está associado com os índices de Gini de cada componente.

\section{Resultados da Pesquisa}

Estratos de rendimento domiciliar per capita

As tabelas 1 a 9 mostram a distribuição percentual dos domicílios particulares permanentes e das pessoas nesses estratos, o percentual do rendimento total e do rendimento de aposentadorias e pensões para o Brasil, Região Sul e Paraná, assim como os dados referentes às esferas urbana e rural, nos anos de 1999, 2001 e 2002.

A tabela 1 indica que a maior concentração percentual de domicílios na população do Brasil está no estrato 3 , enquanto a maior concentração percentual de pessoas na população está no estrato 2 .

Tabela 1. Distribuição percentual dos domicílios, das pessoas, do rendimento total e do rendimento domiciliar de aposentadorias e pensões, em estratos de rendimento domiciliar per capita. Brasil, 1999, 2001 e 2002.

\begin{tabular}{|c|c|c|c|c|c|c|c|c|c|c|c|c|}
\hline \multirow{3}{*}{ 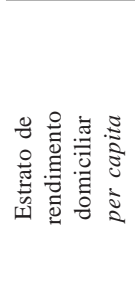 } & \multicolumn{3}{|c|}{$\%$ domicílios na } & \multicolumn{3}{|c|}{$\%$ de pessoas na } & \multicolumn{3}{|c|}{$\%$ do rendimento total } & \multicolumn{3}{|c|}{$\begin{array}{c}\% \text { do rendimento } \\
\text { domiciliar de }\end{array}$} \\
\hline & \multicolumn{3}{|c|}{ população - Br } & \multicolumn{3}{|c|}{ população - Br } & \multicolumn{3}{|c|}{$\mathrm{Br}$} & \multicolumn{3}{|c|}{$\begin{array}{c}\text { aposentadorias e } \\
\text { pensões - } \mathrm{Br}\end{array}$} \\
\hline & 1999 & 2001 & 2002 & 1999 & 2001 & 2002 & 1999 & 2001 & 2002 & 1999 & 2001 & 2002 \\
\hline 1 & 1,5 & 1,8 & 1,3 & 1,2 & 1,6 & 1,1 & - & - & - & - & - & - \\
\hline 2 & 20,5 & 23,5 & 24,2 & 26,6 & 30,3 & 31,2 & 4,3 & 5,4 & 5,8 & 4,2 & 5,0 & 5,2 \\
\hline 3 & 24,5 & 25,2 & 25,8 & 25,0 & 25,6 & 25,9 & 10,0 & 11,5 & 12,0 & 11,0 & 12,4 & 13,4 \\
\hline 4 & 15,0 & 14,6 & 14,6 & 14,6 & 13,8 & 13,7 & 9,6 & 10,3 & 10,5 & 8,5 & 9,7 & 10,0 \\
\hline 5 & 9,2 & 9,1 & 9,1 & 8,4 & 7,9 & 7,9 & 7,8 & 8,3 & 8,5 & 7,5 & 8,4 & 8,5 \\
\hline 6 & 6,2 & 5,9 & 5,7 & 5,6 & 5,1 & 4,9 & 6,7 & 6,9 & 6,8 & 6,1 & 6,7 & 6,5 \\
\hline 7 & 4,5 & 3,8 & 3,8 & 3,9 & 3,2 & 3,2 & 5,7 & 5,4 & 5,4 & 5,4 & 4,9 & 5,6 \\
\hline 8 & 5,2 & 4,8 & 4,7 & 4,4 & 4,1 & 3,9 & 8,2 & 8,5 & 8,3 & 7,9 & 8,8 & 8,3 \\
\hline 9 & 8,3 & 7,2 & 6,8 & 6,7 & 5,7 & 5,4 & 19,6 & 18,8 & 18,3 & 20,2 & 19,0 & 18,6 \\
\hline 10 & 3,5 & 2,8 & 2,8 & 2,6 & 2,0 & 2,0 & 14,8 & 12,7 & 13,3 & 15,3 & 13,0 & 13,1 \\
\hline 11 & 1,7 & 1,4 & 1,2 & 1,0 & 0,8 & 0,7 & 13,3 & 12,2 & 11,0 & 14,0 & 12,1 & 10,8 \\
\hline
\end{tabular}

Fonte: Elaboração própria a partir de $\operatorname{PNAD}(1999 ; 2001 ; 2002)$ 
Ambos estão concentrados nos estratos inferiores da distribuição, ou seja, nos estratos onde estão localizados os relativamente pobres. $\mathrm{O}$ mesmo não acontece com a concentração percentual do rendimento total e do rendimento domiciliar de aposentadorias e pensões, que ocorrem no estrato 9 , no qual estão localizados os relativamente ricos.
No Brasil rural, a maior concentração percentual de domicílios e pessoas na população está no estrato 2, e ainda, $87,4 \%$ dos domicílios obtém rendimentos de até um salário mínimo e meio. O percentual de rendimento total e do rendimento domiciliar de aposentadorias e pensões também está em maior

Tabela 2. Distribuição percentual dos domicílios, das pessoas, do rendimento total e do rendimento domiciliar de aposentadorias e pensões, em estratos de rendimento domiciliar per capita. Brasil rural, 1999, 2001 e 2002.

\begin{tabular}{|c|c|c|c|c|c|c|c|c|c|c|c|c|}
\hline \multirow{2}{*}{ 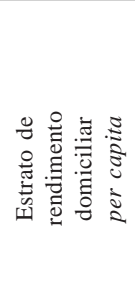 } & \multicolumn{3}{|c|}{$\begin{array}{c}\% \text { domicílios na } \\
\text { população - Br Rural }\end{array}$} & \multicolumn{3}{|c|}{$\begin{array}{c}\% \text { de pessoas na } \\
\text { população - Br Rural }\end{array}$} & \multicolumn{3}{|c|}{$\begin{array}{l}\% \text { do rendimento total - } \\
\text { Br Rural }\end{array}$} & \multicolumn{3}{|c|}{$\begin{array}{l}\text { \% do rendimento } \\
\text { domiciliar de } \\
\text { aposentadorias e } \\
\text { pensões - Br Rural }\end{array}$} \\
\hline & 1999 & 2001 & 2002 & 1999 & 2001 & 2002 & 1999 & 2001 & 2002 & 1999 & 2001 & 2002 \\
\hline 1 & 1,4 & 1,3 & 0,9 & 1,2 & 1,1 & 0,7 & - & - & - & - & - & - \\
\hline 2 & 44,1 & 49,0 & 49,8 & 53,9 & 60,0 & 60,5 & 19,1 & 23,0 & 25,0 & 16,7 & 17,9 & 18,5 \\
\hline 3 & 29,9 & 28,1 & 29,0 & 26,4 & 23,8 & 24,3 & 25,0 & 26,1 & 27,7 & 34,6 & 35,7 & 38,6 \\
\hline 4 & 11,5 & 10,7 & 10,0 & 9,0 & 7,8 & 7,4 & 14,1 & 14,3 & 14,2 & 15,8 & 17,2 & 16,5 \\
\hline 5 & 5,0 & 4,8 & 4,6 & 3,6 & 3,1 & 3,2 & 7,9 & 8,1 & 8,7 & 8,6 & 8,6 & 8,3 \\
\hline 6 & 2,5 & 1,8 & 2,0 & 2,0 & 1,3 & 1,4 & 5,7 & 4,5 & 4,9 & 4,9 & 4,0 & 3,7 \\
\hline 7 & 1,5 & 1,0 & 1,1 & 1,2 & 0,7 & 0,8 & 4,2 & 3,0 & 3,4 & 2,6 & 1,9 & 2,7 \\
\hline 8 & 1,5 & 1,3 & 1,1 & 1,1 & 0,9 & 0,8 & 5,0 & 4,7 & 4,2 & 3,4 & 3,2 & 2,8 \\
\hline 9 & 1,8 & 1,4 & 1,0 & 1,2 & 0,9 & 0,7 & 8,6 & 7,6 & 5,8 & 8,8 & 4,5 & 3,8 \\
\hline 10 & 0,6 & 0,4 & 0,4 & 0,4 & 0,2 & 0,2 & 5,4 & 3,9 & 3,8 & 2,9 & 3,4 & 2,9 \\
\hline 11 & 0,2 & 0,2 & 0,1 & 0,1 & 0,1 & 0,1 & 5,1 & 4,9 & 2,4 & 1,6 & 3,6 & 2,3 \\
\hline
\end{tabular}

Fonte: Elaboração própria a partir de PNAD $(1999 ; 2001 ; 2002)$

proporção no estrato 3, ou seja, onde estão localizados os relativamente pobres. Se considerarmos o intervalo até um salário mínimo e meio os dados indicam que a concentração dos rendimentos domiciliares das aposentadorias e pensões é alta e crescente, já que, em 2002, 73,6\% desse rendimento estavam nesses estratos, contra 67,1\% de 1999 .

A tabela 3 evidencia que o estrato 3 contém o maior percentual de domicílios na população do Brasil urbano. Observa-se que o percentual de pessoas na população está crescendo nos estratos 2 e 3 , ou seja, nos relativamente pobres. Com relação ao percentual do rendimento total e rendimento domiciliar de aposentadorias e pensões, a maior concentração, ainda que decrescente, está no estrato 9 . O estrato 10 apresenta a segunda maior concentração de rendimentos, mas também decrescente. $\mathrm{O}$ estrato 3 absorve a terceira maior concentração de rendimentos. 
Ferreira, C. R; Souza, S. C. I.

Tabela 3. Distribuição percentual dos domicílios, das pessoas, do rendimento total e do rendimento domiciliar de aposentadorias e pensões, em estratos de rendimento domiciliar per capita. Brasil urbano, 1999, 2001 e 2002.

\begin{tabular}{|c|c|c|c|c|c|c|c|c|c|c|c|c|}
\hline \multirow{2}{*}{ 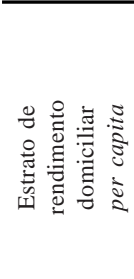 } & \multicolumn{3}{|c|}{$\begin{array}{c}\% \text { domicílios na } \\
\text { população - Br urbano }\end{array}$} & \multicolumn{3}{|c|}{$\begin{array}{c}\% \text { de pessoas na } \\
\text { população - Br urbano }\end{array}$} & \multicolumn{3}{|c|}{$\begin{array}{l}\% \text { do rendimento total - } \\
\qquad \mathrm{Br} \text { urbano }\end{array}$} & \multicolumn{3}{|c|}{$\begin{array}{c}\text { \% do rendimento } \\
\text { domiciliar de } \\
\text { aposentadorias e } \\
\text { pensões - Br urbano }\end{array}$} \\
\hline & 1999 & 2001 & 2002 & 1999 & 2001 & 2002 & 1999 & 2001 & 2002 & 1999 & 2001 & 2002 \\
\hline 1 & 1,3 & 1,6 & 1,1 & 1,2 & 1,4 & 1,0 & - & - & - & - & - & - \\
\hline 2 & 18,3 & 22,4 & 23,1 & 23,5 & 28,7 & 29,4 & 4,1 & 5,6 & 6,0 & 4,5 & 5,7 & 5,8 \\
\hline 3 & 25,5 & 26,6 & 27,2 & 26,1 & 27,0 & 27,5 & 10,7 & 12,8 & 13,4 & 12,2 & 14,1 & 15,0 \\
\hline 4 & 15,8 & 15,3 & 15,3 & 15,6 & 14,7 & 14,6 & 10,6 & 11,6 & 11,7 & 9,2 & 10,7 & 10,8 \\
\hline 5 & 9,8 & 9,4 & 9,3 & 9,1 & 8,2 & 8,0 & 8,7 & 9,1 & 9,1 & 8,1 & 8,9 & 9,0 \\
\hline 6 & 6,7 & 6,1 & 5,8 & 6,1 & 5,3 & 5,1 & 7,5 & 7,6 & 7,4 & 6,6 & 7,2 & 6,6 \\
\hline 7 & 4,6 & 3,7 & 3,9 & 4,1 & 3,2 & 3,2 & 6,1 & 5,6 & 5,7 & 5,7 & 5,1 & 5,6 \\
\hline 8 & 5,5 & 4,8 & 4,8 & 4,7 & 4,0 & 4,0 & 8,9 & 8,9 & 9,0 & 8,4 & 9,6 & 9,0 \\
\hline 9 & 8,1 & 6,8 & 6,3 & 6,7 & 5,4 & 5,1 & 20,1 & 18,7 & 17,9 & 20,2 & 18,8 & 18,3 \\
\hline 10 & 3,1 & 2,3 & 2,3 & 2,4 & 1,6 & 1,7 & 13,7 & 11,0 & 11,7 & 14,6 & 10,5 & 10,8 \\
\hline 11 & 1,2 & 1,0 & 0,9 & 0,8 & 0,6 & 0,6 & 9,6 & 9,2 & 8,3 & 10,5 & 9,4 & 8,9 \\
\hline
\end{tabular}

Fonte: Elaboração própria a partir de $\operatorname{PNAD}(1999 ; 2001 ; 2002)$

A tabela 4 aponta que a maior concentração percentual de domicílios na população e pessoas na população da Região Sul está no estrato 3, enquanto a maior concentração percentual do rendimento total e rendimento domiciliar de aposentadorias e pensões estão nos estratos superiores, a partir do estrato 9.

Tabela 4. Distribuição percentual dos domicílios, das pessoas, do rendimento total e do rendimento domiciliar de aposentadorias e pensões, em estratos de rendimento domiciliar per capita. Região sul, 1999, 2001 e 2002.

\begin{tabular}{|c|c|c|c|c|c|c|c|c|c|c|c|c|}
\hline \multirow{2}{*}{ 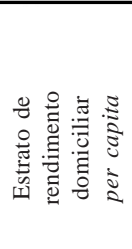 } & \multicolumn{3}{|c|}{$\begin{array}{l}\text { \% domicílios na } \\
\text { população - Sul }\end{array}$} & \multicolumn{3}{|c|}{$\begin{array}{l}\% \text { de pessoas na } \\
\text { população - Sul }\end{array}$} & \multicolumn{3}{|c|}{$\begin{array}{l}\% \text { do rendimento total - } \\
\text { Sul }\end{array}$} & \multicolumn{3}{|c|}{$\begin{array}{c}\% \text { do rendimento } \\
\text { domiciliar de } \\
\text { aposentadorias e pensões - } \\
\text { Sul }\end{array}$} \\
\hline & 1999 & 2001 & 2002 & 1999 & 2001 & 2002 & 1999 & 2001 & 2002 & 1999 & 2001 & 2002 \\
\hline 1 & 1,2 & 1,1 & 0,7 & 1,0 & 1,0 & 0,6 & - & - & - & - & - & - \\
\hline 2 & 13,9 & 15,0 & 14,6 & 18,0 & 19,4 & 19,1 & 2,7 & 3,2 & 3,4 & 2,7 & 2,7 & 2,7 \\
\hline 3 & 23,7 & 23,8 & 25,4 & 25,0 & 25,6 & 26,8 & 8,9 & 10,1 & 11,0 & 9,8 & 10,2 & 11,7 \\
\hline 4 & 16,6 & 17,0 & 17,2 & 17,0 & 17,2 & 17,3 & 9,9 & 11,0 & 11,5 & 8,9 & 10,2 & 10,5 \\
\hline 5 & 10,8 & 12,1 & 12,0 & 10,1 & 11,0 & 10,8 & 8,2 & 9,9 & 10,1 & 8,5 & 9,9 & 10,3 \\
\hline 6 & 7,6 & 7,4 & 7,5 & 7,0 & 6,8 & 6,7 & 7,4 & 7,9 & 8,1 & 6,7 & 7,3 & 7,2 \\
\hline 7 & 5,1 & 4,7 & 4,8 & 4,6 & 4,2 & 4,3 & 6,0 & 5,9 & 6,3 & 5,4 & 5,0 & 5,9 \\
\hline 8 & 6,1 & 6,0 & 5,9 & 4,3 & 5,2 & 5,1 & 8,6 & 9,4 & 9,5 & 8,4 & 9,8 & 9,4 \\
\hline 9 & 9,2 & 8,1 & 7,9 & 7,7 & 6,4 & 6,6 & 19,8 & 18,2 & 19,4 & 18,5 & 19,1 & 18,3 \\
\hline 10 & 4,0 & 3,0 & 2,9 & 3,1 & 2,2 & 2,2 & 15,4 & 11,8 & 12,0 & 16,6 & 12,8 & 11,7 \\
\hline 11 & 1,8 & 1,6 & 1,1 & 1,2 & 1,0 & 0,7 & 13,1 & 12,5 & 8,7 & 14,4 & 13,0 & 12,2 \\
\hline
\end{tabular}

Fonte: Elaboração própria a partir de PNAD(1999; 2001; 2002) 
Para a Região Sul rural, as informações são as de que a maior concentração de domicílios e pessoas na população está nos estratos inferiores, ou seja, nos estratos 2,3, e 4. Observa-se, também, que o percentual dos rendimentos total e de aposentadorias e pensões está concentrado nos estratos inferiores da distribuição, coincidindo com o comportamento do Brasil rural, verificado na tabela 2. Na Região Sul rural, $67,2 \%$ dos rendimentos domiciliares das aposentadorias e pensões estavam, em 2002, localizados nos estratos 3, 4 e 5, isto é, no intervalo de meio a dois salários mínimos. Em 1999, esse percentual era de $65,5 \%$.

Tabela 5. Distribuição percentual dos domicílios, das pessoas, do rendimento total e do rendimento domiciliar de aposentadorias e pensões, em estratos de rendimento domiciliar per capita. Região sul rural, 1999, 2001 e 2002.

\begin{tabular}{|c|c|c|c|c|c|c|c|c|c|c|c|c|}
\hline \multirow{2}{*}{ 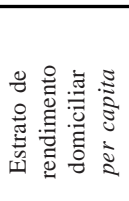 } & \multicolumn{3}{|c|}{$\begin{array}{c}\text { \% domicílios na } \\
\text { população - Sul rural }\end{array}$} & \multicolumn{3}{|c|}{$\begin{array}{c}\text { \% de pessoas na } \\
\text { população }- \text { Sul rural }\end{array}$} & \multicolumn{3}{|c|}{$\begin{array}{l}\% \text { do rendimento total - } \\
\text { Sul rural }\end{array}$} & \multicolumn{3}{|c|}{$\begin{array}{l}\text { \% do rendimento } \\
\text { domiciliar de } \\
\text { aposentadorias e } \\
\text { pensões - Sul rural }\end{array}$} \\
\hline & 1999 & 2001 & 2002 & 1999 & 2001 & 2002 & 1999 & 2001 & 2002 & 1999 & 2001 & 2002 \\
\hline 1 & 0,8 & 0,6 & 0,5 & 0,7 & 0,5 & 0,3 & - & - & - & - & - & - \\
\hline 2 & 27,1 & 29,7 & 28,1 & 33,6 & 37,0 & 34,3 & 9,2 & 10,2 & 10,0 & 8,2 & 7,8 & 5,7 \\
\hline 3 & 31,7 & 29,9 & 31,0 & 31,4 & 29,5 & 30,8 & 21,4 & 21,1 & 21,8 & 28,0 & 25,6 & 27,8 \\
\hline 4 & 18,0 & 16,3 & 17,3 & 16,0 & 14,4 & 15,6 & 18,0 & 16,8 & 18,1 & 21,7 & 21,6 & 22,7 \\
\hline 5 & 9,2 & 10,8 & 10,3 & 7,5 & 8,4 & 8,7 & 11,8 & 13,8 & 14,2 & 15,3 & 17,6 & 16,7 \\
\hline 6 & 4,5 & 4,3 & 4,6 & 3,8 & 3,7 & 3,6 & 7,8 & 7,9 & 7,6 & 8,6 & 7,8 & 7,6 \\
\hline 7 & 2,7 & 2,3 & 2,8 & 2,4 & 1,7 & 2,4 & 5,9 & 4,5 & 6,1 & 5,3 & 4,5 & 5,2 \\
\hline 8 & 2,2 & 2,9 & 2,7 & 1,8 & 2,3 & 2,2 & 5,6 & 7,6 & 7,2 & 4,5 & 5,7 & 4,3 \\
\hline 9 & 2,6 & 2,5 & 2,1 & 1,9 & 1,7 & 1,5 & 9,2 & 8,0 & 7,9 & 7,7 & 5,1 & 5,6 \\
\hline 10 & 0,9 & 0,6 & 0,6 & 0,8 & 0,4 & 0,5 & 7,5 & 4,4 & 4,7 & 0,5 & 3,4 & 2,3 \\
\hline 11 & 0,3 & 0,2 & 0,1 & 0,2 & 0,3 & 0,1 & 3,7 & 5,6 & 2,4 & 0,3 & 0,9 & 2,0 \\
\hline
\end{tabular}

Fonte: Elaboração própria a partir de $\operatorname{PNAD}(1999 ; 2001 ; 2002)$

A tabela 6 indica que a maior concentração percentual de domicílios na população e pessoas na população da Região Sul urbano está no estrato 3, enquanto a maior concentração percentual do rendimento total e rendimento domiciliar de aposentadorias e pensões está nos estratos superiores, a partir do estrato 9.

Tabela 6. Distribuição percentual dos domicílios, das pessoas, do rendimento total e do rendimento domiciliar de aposentadorias e pensões, em estratos de rendimento domiciliar per capita. Região sul urbano, 1999, 2001 e 2002.

\begin{tabular}{|c|c|c|c|c|c|c|c|c|c|c|c|c|}
\hline \multirow{2}{*}{ 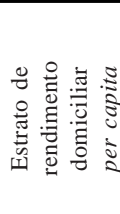 } & \multicolumn{3}{|c|}{$\begin{array}{c}\text { \% domicílios na } \\
\text { população - Sul urbano }\end{array}$} & \multicolumn{3}{|c|}{$\begin{array}{c}\% \text { de pessoas na } \\
\text { população }- \text { Sul urbano }\end{array}$} & \multicolumn{3}{|c|}{$\begin{array}{l}\% \text { do rendimento total - } \\
\text { Sul urbano }\end{array}$} & \multicolumn{3}{|c|}{$\begin{array}{c}\text { \% do rendimento } \\
\text { domiciliar de } \\
\text { aposentadorias e } \\
\text { pensões Sul urbano }\end{array}$} \\
\hline & 1999 & 2001 & 2002 & 1999 & 2001 & 2002 & 1999 & 2001 & 2002 & 1999 & 2001 & 2002 \\
\hline 1 & 1,1 & 1,0 & 0,6 & 1,0 & 1,0 & 0,5 & - & - & - & - & - & - \\
\hline 2 & 11,9 & 13,3 & 12,4 & 15,1 & 16,9 & 16,3 & 2,3 & 2,9 & 3,0 & 2,7 & 2,7 & 3,0 \\
\hline 3 & 23,4 & 23,9 & 25,9 & 24,3 & 25,6 & 27,1 & 8,4 & 10,1 & 11,0 & 9,9 & 10,4 & 12,5 \\
\hline 4 & 16,2 & 17,4 & 17,7 & 16,8 & 17,7 & 18,0 & 9,4 & 11,3 & 11,9 & 8,9 & 10,4 & 10,8 \\
\hline 5 & 11,2 & 12,7 & 12,4 & 10,7 & 11,8 & 11,2 & 8,4 & 10,6 & 10,4 & 9,3 & 10,4 & 10,9 \\
\hline 6 & 8,3 & 7,8 & 7,6 & 7,9 & 7,2 & 6,9 & 8,0 & 8,4 & 8,3 & 7,3 & 7,6 & 7,0 \\
\hline 7 & 5,7 & 5,0 & 5,2 & 5,3 & 4,5 & 4,7 & 6,5 & 6,4 & 6,8 & 6,2 & 5,3 & 6,3 \\
\hline 8 & 6,6 & 6,4 & 6,4 & 6,0 & 5,7 & 5,7 & 9,3 & 10,1 & 10,5 & 8,5 & 11,5 & 10,8 \\
\hline 9 & 9,7 & 8,2 & 8,1 & 8,5 & 6,6 & 7,0 & 21,1 & 18,6 & 20,5 & 18,7 & 19,9 & 19,4 \\
\hline 10 & 4,2 & 2,8 & 2,6 & 3,2 & 2,1 & 2,0 & 15,7 & 11,0 & 10,7 & 17,8 & 10,4 & 9,4 \\
\hline 11 & 1,6 & 1,4 & 0,9 & 1,1 & 0,9 & 0,6 & 11,0 & 10,6 & 6,9 & 10,8 & 11,4 & 9,9 \\
\hline
\end{tabular}

Fonte: Elaboração própria a partir de PNAD(1999; 2001; 2002) 
A tabela 7 mostra que o percentual de domicílios e de pessoas na população do Paraná, estão em maior quantidade no estrato 3, enquanto o percentual de rendimento total e de aposentadorias e pensões estão concentrados no estrato 9, coincidindo com o Brasil, Brasil urbano, Região Sul e Região Sul urbana.

Tabela 7. Distribuição percentual dos domicílios, das pessoas, do rendimento total e do rendimento domiciliar de aposentadorias e pensões, em estratos de rendimento domiciliar per capita. Paraná, 1999, 2001 e 2002.

\begin{tabular}{|c|c|c|c|c|c|c|c|c|c|c|c|c|}
\hline \multirow{2}{*}{ 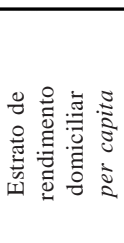 } & \multicolumn{3}{|c|}{$\begin{array}{c}\text { \% domicílios na } \\
\text { população - Paraná }\end{array}$} & \multicolumn{3}{|c|}{$\begin{array}{c}\% \text { de pessoas na } \\
\text { população - Paraná }\end{array}$} & \multicolumn{3}{|c|}{$\begin{array}{c}\% \text { do rendimento total - } \\
\text { Paraná }\end{array}$} & \multicolumn{3}{|c|}{$\begin{array}{l}\text { \% do rendimento } \\
\text { domiciliar de } \\
\text { aposentadorias e } \\
\text { pensões - Paraná }\end{array}$} \\
\hline & 1999 & 2001 & 2002 & 1999 & 2001 & 2002 & 1999 & 2001 & 2002 & 1999 & 2001 & 2002 \\
\hline 1 & 1,6 & 1,6 & 0,9 & 1,5 & 1,4 & 0,6 & & & & & & \\
\hline 2 & 17,3 & 18,4 & 16,5 & 21,2 & 23,1 & 21,3 & 3,4 & 4,0 & 4,0 & 4,4 & 4,0 & 3,4 \\
\hline 3 & 25,7 & 25,9 & 28,1 & 26,8 & 26,9 & 29,0 & 10,2 & 11,4 & 12,5 & 12,9 & 13,6 & 14,4 \\
\hline 4 & 16,1 & 16,5 & 16,3 & 16,3 & 16,1 & 16,3 & 10,2 & 11,1 & 11,4 & 10,1 & 11,4 & 11,0 \\
\hline 5 & 9,4 & 10,3 & 10,3 & 8,7 & 9,3 & 9,3 & 7,6 & 9,1 & 9,2 & 8,7 & 9,9 & 9,5 \\
\hline 6 & 6,8 & 6,7 & 6,8 & 6,2 & 6,3 & 6,0 & 7,1 & 7,9 & 7,7 & 6,0 & 7,8 & 6,9 \\
\hline 7 & 4,4 & 4,2 & 4,2 & 4,0 & 3,6 & 3,6 & 5,5 & 5,6 & 5,7 & 4,8 & 3,6 & 4,8 \\
\hline 8 & 5,2 & 5,4 & 5,4 & 4,7 & 4,7 & 4,8 & 8,2 & 9,0 & 9,4 & 7,9 & 8,1 & 8,7 \\
\hline 9 & 8,3 & 6,9 & 7,7 & 6,8 & 5,6 & 6,4 & 18,6 & 17,2 & 19,9 & 16,5 & 19,2 & 16,2 \\
\hline 10 & 3,6 & 2,7 & 2,9 & 2,7 & 2,1 & 2,1 & 14,9 & 12,3 & 12,5 & 16,3 & 12,6 & 14,6 \\
\hline 11 & 1,7 & 1,4 & 0,9 & 1,2 & 1,0 & 0,6 & 14,2 & 12,5 & 7,8 & 12,5 & 9,8 & 10,5 \\
\hline
\end{tabular}

Fonte: Elaboração própria a partir de PNAD(1999; 2001; 2002)

No Paraná rural, a maior concentração de domicílios e população está nos estratos inferiores, e os percentuais dos rendimentos total e de aposentadorias e pensões também estão concentrados nos estratos inferiores da distribuição. Repete-se, assim, o que já havia sido verificado no
Brasil rural e Região Sul rural. Se considerarmos o intervalo até um e meio a dois salários mínimos, os dados indicam que a concentração dos rendimentos domiciliares das aposentadorias e pensões é alta, concentrando, em média, $77,8 \%$

Tabela 8. Distribuição percentual dos domicílios, das pessoas, do rendimento total e do rendimento domiciliar de aposentadorias e pensões, em estratos de rendimento domiciliar per capita. Paraná rural, 1999, 2001 e 2002.

\begin{tabular}{|c|c|c|c|c|c|c|c|c|c|c|c|c|}
\hline \multirow{2}{*}{ 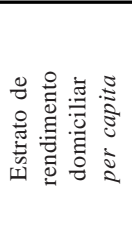 } & \multicolumn{3}{|c|}{$\begin{array}{c}\text { \% domicílios na } \\
\text { população - Paraná } \\
\text { rural }\end{array}$} & \multicolumn{3}{|c|}{$\begin{array}{c}\text { \% de pessoas na } \\
\text { população - Paraná } \\
\text { rural }\end{array}$} & \multicolumn{3}{|c|}{$\begin{array}{c}\% \text { do rendimento total - } \\
\text { Paraná rural }\end{array}$} & \multicolumn{3}{|c|}{$\begin{array}{c}\text { \% do rendimento } \\
\text { domiciliar de } \\
\text { aposentadorias e } \\
\text { pensões - Paraná rural }\end{array}$} \\
\hline & 1999 & 2001 & 2002 & 1999 & 2001 & 2002 & 1999 & 2001 & 2002 & 1999 & 2001 & 2002 \\
\hline 1 & 1,1 & 0,7 & 0,5 & 0,9 & 0,5 & 0,2 & - & - & - & - & - & - \\
\hline 2 & 35,0 & 38,4 & 36,8 & 41,9 & 48,1 & 43,7 & 13,4 & 14,0 & 14,2 & 13,3 & 12,7 & 7,5 \\
\hline 3 & 33,1 & 30,9 & 33,8 & 32,5 & 28,2 & 32,7 & 26,5 & 21,3 & 25,8 & 36,5 & 30,0 & 35,7 \\
\hline 4 & 14,9 & 11,8 & 12,1 & 12,3 & 9,7 & 10,8 & 16,6 & 12,3 & 14,0 & 22,0 & 20,9 & 18,4 \\
\hline 5 & 5,7 & 7,5 & 6,2 & 4,2 & 5,4 & 4,6 & 8,0 & 9,7 & 8,6 & 8,2 & 15,3 & 12,8 \\
\hline 6 & 3,0 & 2,7 & 3,6 & 2,5 & 2,6 & 2,5 & 6,2 & 6,0 & 5,9 & 7,3 & 5,2 & 5,2 \\
\hline 7 & 2,5 & 1,9 & 2,1 & 2,2 & 1,2 & 1,9 & 6,6 & 3,5 & 5,3 & 4,5 & 3,2 & 3,5 \\
\hline 8 & 1,9 & 2,4 & 2,1 & 1,4 & 1,9 & 1,5 & 5,3 & 6,9 & 5,2 & 5,6 & 5,4 & 3,9 \\
\hline 9 & 1,7 & 2,2 & 2,0 & 1,3 & 1,3 & 1,4 & 7,0 & 7,4 & 8,5 & 1,9 & 3,7 & 8,6 \\
\hline 10 & 1,0 & 0,9 & 0,5 & 0,7 & 0,6 & 0,5 & 8,5 & 6,6 & 5,8 & 0,8 & 1,0 & 3,8 \\
\hline 11 & 0,1 & 0,4 & 0,3 & 0,1 & 0,5 & 0,2 & 2,0 & 12,2 & 6,6 & 0,0 & 2,5 & 0,6 \\
\hline
\end{tabular}

Fonte: Elaboração própria a partir de PNAD(1999; 2001; 2002) 
A tabela 9 mostra que o percentual de domicílios e de pessoas na população estão em maior quantidade no estrato 3 , enquanto o percentual de rendimento total e de aposentadorias e pensões estão concentrados no estrato 9, coincidindo com o Brasil, Brasil urbano, Região Sul e Região Sul urbana.

Tabela 9. Distribuição percentual dos domicílios, das pessoas, do rendimento total e do rendimento domiciliar de aposentadorias e pensões, em estratos de rendimento domiciliar per capita. Paraná urbano, 1999, 2001 e 2002.

\begin{tabular}{|c|c|c|c|c|c|c|c|c|c|c|c|c|}
\hline \multirow[t]{2}{*}{ 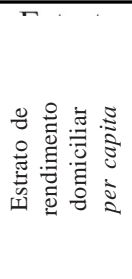 } & \multicolumn{3}{|c|}{$\begin{array}{c}\text { \% domicílios na } \\
\text { população - Paraná } \\
\text { urbano }\end{array}$} & \multicolumn{3}{|c|}{$\begin{array}{c}\text { \% de pessoas na } \\
\text { população - Paraná } \\
\text { urbano }\end{array}$} & \multicolumn{3}{|c|}{$\begin{array}{c}\% \text { do rendimento total - } \\
\text { Paraná urbano }\end{array}$} & \multicolumn{3}{|c|}{$\begin{array}{c}\text { \% do rendimento } \\
\text { domiciliar de } \\
\text { aposentadorias e } \\
\text { pensões - Paraná } \\
\text { urbano }\end{array}$} \\
\hline & 1999 & 2001 & 2002 & 1999 & 2001 & 2002 & 1999 & 2001 & 2002 & 1999 & 2001 & 2002 \\
\hline 1 & 1,5 & 1,4 & 0,7 & 1,3 & 1,4 & 0,5 & - & - & - & - & - & - \\
\hline 2 & 16,2 & 17,4 & 15,0 & 19,5 & 21,2 & 19,3 & 3,3 & 4,0 & 3,9 & 5,1 & 5,0 & 4,6 \\
\hline 3 & 26,8 & 27,1 & 29,9 & 27,5 & 28,1 & 30,6 & 10,6 & 12,5 & 13,6 & 15,2 & 16,8 & 18,3 \\
\hline 4 & 16,1 & 17,7 & 17,7 & 16,4 & 17,1 & 17,9 & 10,3 & 12,4 & 12,9 & 11,4 & 13,2 & 13,5 \\
\hline 5 & 9,8 & 10,6 & 10,1 & 9,0 & 9,7 & 9,1 & 8,0 & 9,8 & 9,3 & 11,3 & 11,5 & 10,5 \\
\hline 6 & 7,3 & 6,4 & 6,2 & 6,7 & 6,0 & 5,4 & 7,7 & 7,8 & 7,1 & 6,8 & 8,1 & 6,7 \\
\hline 7 & 4,2 & 4,2 & 4,5 & 4,0 & 3,8 & 3,7 & 5,6 & 6,0 & 6,0 & 5,4 & 3,5 & 5,2 \\
\hline 8 & 5,1 & 5,5 & 5,5 & 4,8 & 4,7 & 5,1 & 8,4 & 9,4 & 10,4 & 6,4 & 10,1 & 9,1 \\
\hline 9 & 8,2 & 6,5 & 7,2 & 7,0 & 5,4 & 6,2 & 19,4 & 17,2 & 20,0 & 16,4 & 20,9 & 16,8 \\
\hline 10 & 3,4 & 2,1 & 2,4 & 2,6 & 1,8 & 1,7 & 14,4 & 11,2 & 10,3 & 13,5 & 6,0 & 9,5 \\
\hline 11 & 1,5 & 1,0 & 0,8 & 1,1 & 0,8 & 0,5 & 12,2 & 9,6 & 6,5 & 8,6 & 4,8 & 5,8 \\
\hline
\end{tabular}

Fonte: Elaboração própria a partir de $\operatorname{PNAD}(1999 ; 2001 ; 2002)$

Por meio da estratificação do percentual do rendimento total e do rendimento domiciliar de aposentadorias e pensões, nota-se que esses rendimentos estão sempre concentrados, seja nos estratos inferiores, para o meio rural, ou nos estratos superiores para os demais.

Nota-se que no Brasil, Brasil Urbano, Sul, Sul Urbano, Paraná, e Paraná Urbano, os estratos que concentram o maior número de domicílios não detêm o maior percentual de renda total e rendimento de aposentadorias e pensões. A renda total está concentrada nos estratos superiores, nos quais estão os relativamente ricos. Esse comportamento é diferente na esfera rural brasileira, pois no Brasil rural, região sul rural e Paraná rural, apresentam o maior número de domicílios e renda total nos estratos inferiores, nos quais estão os relativamente pobres.

Analisando somente os rendimentos de aposentadorias e pensões, observa-se que estão nos estratos superiores (relativamente ricos) a predominância desse tipo de rendimento. Essa relação é diferenciada se analisarmos o Brasil rural, Região sul rural e Paraná rural, nos quais esse rendimento está concentrado nos estratos inferiores. De forma geral, verifica-se um descompasso entre os estratos que concentram mais domicílios e consequentemente, mais pessoas, e a distribuição do rendimento total e das aposentadorias e pensões. Além disso, cabe acrescentar que essa tendência não se verifica no meio rural estratificado .

\section{Resultados da Decomposição do Índice de Gini}

A tabela 10 mostra os resultados da decomposição do índice de Gini da distribuição do rendimento domiciliar per capita no Brasil, nos anos de 1999, 2001 e 2002, considerando seis componentes: rendimento do trabalho principal das pessoas ocupadas, rendimento de outros trabalhos, aposentadorias e pensões, doações, aluguéis e uma parcela constituída por juros, dividendos e outros rendimentos. Em 1999, apenas o rendimento do trabalho principal e as doações têm razão de concentração $\left(\mathrm{C}_{\mathrm{h}}\right)$ menor do que o índice de Gini 
global. Embora a razão de concentração das doações seja a mais baixa para os três anos analisados, ela ainda é positiva, indicando que o valor das doações per capita tende a crescer com o rendimento domiciliar per capita.

Nota-se, também, que os rendimentos do trabalho principal, para o período analisado, devido à sua grande participação no total, dão origem à maior parcela do índice de Gini.
Entre os demais componentes do rendimento, as aposentadorias e pensões têm papel de realce. Em 1999 representava $17,8 \%$ do rendimento total, dando origem a 18,1\% do índice de Gini. Em 2002, significou $18,7 \%$ do rendimento total, participando com $18,9 \%$ do índice de Gini, evidenciando um crescimento de $0,9 \%$ na participação da renda total e $0,8 \%$ na formação do índice de Gini global. A esses

Tabela 10. Decomposição do índice de Gini do rendimento domiciliar per capita no Brasil, em 1999, 2001 e 2002: participação do componente no rendimento total $\left(\phi_{h}\right)$, razão de concentração $\left(C_{h}\right)$ e parcela do componente no índice de Gini geral $\left(\phi_{h} C_{h}\right)$.

\begin{tabular}{|c|c|c|c|c|c|c|c|c|c|}
\hline \multirow{3}{*}{$\begin{array}{l}\text { Componente } \\
\text { do } \\
\text { rendimento }\end{array}$} & \multicolumn{9}{|c|}{ Brasil } \\
\hline & 1999 & 2001 & 2002 & 1999 & 2001 & 2002 & 1999 & 2001 & 2002 \\
\hline & $\%\left(\phi_{h}\right)$ & $\%\left(\phi_{h}\right)$ & $\%\left(\phi_{h}\right)$ & $C_{h}$ & $C_{h}$ & $C_{h}$ & $\phi_{h} C_{h}$ & $\phi_{h} C_{h}$ & $\phi_{h} C_{h}$ \\
\hline $\begin{array}{l}\text { Trabalho } \\
\text { Principal }\end{array}$ & 75,5 & 74,7 & 74,2 & 0,579 & 0,581 & 0,575 & 0,437 & 0,434 & 0,426 \\
\hline $\begin{array}{l}\text { Outros } \\
\text { trabalhos }\end{array}$ & 3,0 & 3,2 & 3,2 & 0,745 & 0,785 & 0,777 & 0,022 & 0,025 & 0,025 \\
\hline $\begin{array}{l}\text { Apos. e } \\
\text { pensões }\end{array}$ & 17,8 & 18,5 & 18,7 & 0,603 & 0,603 & 0,592 & 0,107 & 0,112 & 0,111 \\
\hline Aluguéis & 2,2 & 1,9 & 1,9 & 0,803 & 0,797 & 0,803 & 0,018 & 0,015 & 0,015 \\
\hline Doações & 0,7 & 0,7 & 0,8 & 0,354 & 0,395 & 0,429 & 0,002 & 0,003 & 0,003 \\
\hline Juros, etc & 0,8 & 0,9 & 1,3 & 0,695 & 0,539 & 0,512 & 0,006 & 0,005 & 0,007 \\
\hline Total & 100,0 & 100,0 & 100,0 & 0,592 & 0,594 & 0,587 & 0,592 & 0,594 & 0,587 \\
\hline
\end{tabular}

Fonte: Elaboração própria a partir de PNAD (1999, 2001 e 2002)

incrementos observados pelas aposentadorias e pensões contrapõe-se um movimento de decréscimo tanto das participações dessa parcela no total dos rendimentos, quanto das suas participações no índice de Gini para o componente trabalho principal.

Nas áreas urbanas (tabela 11), a participação do rendimento das aposentadorias e pensões também é crescente. Em 1999, esse rendimento representou $17,5 \%$ do rendimento total e originou $17,5 \%$ do índice de Gini. Em 2001 e 2002, houve um crescimento da participação, passando de $18,1 \%$ para $18,3 \%$ do rendimento total, contribuindo com $18,2 \%$ e $18,4 \%$ do índice de Gini. No período, o crescimento da participação das aposentadorias e pensões na renda total foi de $0,8 \%$ e $0,9 \%$ na formação do índice de Gini. Observa-se que a razão de concentração de aposentadorias e pensões para esses anos é superior ao índice de Gini.

Tabela 11. Decomposição do índice de Gini do rendimento domiciliar per capita no Brasil urbano, em 1999, 2001 e 2002: participação do componente no rendimento total $\left(\phi_{h}\right)$, razão de concentração $\left(C_{h}\right)$ e parcela do componente no índice de $\operatorname{Gini}$ geral $\left(\phi_{h} C_{h}\right)$.

\begin{tabular}{|c|c|c|c|c|c|c|c|c|c|}
\hline \multirow{3}{*}{$\begin{array}{c}\text { Componente } \\
\text { do } \\
\text { rendimento }\end{array}$} & \multicolumn{9}{|c|}{ Brasil urbano } \\
\hline & 1999 & 2001 & 2002 & 1999 & 2001 & 2002 & 1999 & 2001 & 2002 \\
\hline & $\%\left(\phi_{h}\right)$ & $\%\left(\phi_{h}\right)$ & $\%\left(\phi_{h}\right)$ & $C_{h}$ & $C_{h}$ & $C_{h}$ & $\phi_{h} C_{h}$ & $\phi_{h} C_{h}$ & $\phi_{h} C_{h}$ \\
\hline $\begin{array}{l}\text { Trabalho } \\
\text { Principal }\end{array}$ & 75,4 & 74,7 & 74,1 & 0,545 & 0,750 & 0,544 & 0,411 & 0,411 & 0,404 \\
\hline $\begin{array}{l}\text { Outros } \\
\text { trabalhos }\end{array}$ & 3,3 & 3,6 & 3,7 & 0,774 & 0,799 & 0,805 & 0,026 & 0,029 & 0,030 \\
\hline $\begin{array}{l}\text { Apos. e } \\
\text { pensões }\end{array}$ & 17,5 & 18,1 & 18,3 & 0,562 & 0,567 & 0,561 & 0,098 & 0,103 & 0,103 \\
\hline Aluguéis & 2,4 & 2,2 & 2,1 & 0,796 & 0,794 & 0,796 & 0,019 & 0,017 & 0,017 \\
\hline Doações & 0,7 & 0,7 & 0,8 & 0,242 & 0,328 & 0,375 & 0,002 & 0,002 & 0,003 \\
\hline Juros, etc & 0,6 & 0,7 & 1,0 & 0,610 & 0,454 & 0,381 & 0,004 & 0,003 & 0,004 \\
\hline Total & 100,0 & 100,0 & 100,0 & 0,560 & 0,565 & 0,559 & 0,560 & 0,565 & 0,559 \\
\hline
\end{tabular}

Fonte: Elaboração própria a partir de PNAD (1999, 2001 e 2002) 
O papel das aposentadorias e pensões é mais salientado na formação do rendimento domiciliar per capita no Brasil rural, conforme se pode ver na tabela 12. Em 1999, o rendimento de aposentadorias e pensões representou $17,4 \%$ do rendimento total e originou 17,5\% do índice de Gini. Em 2001, esse rendimento representou $21,7 \%$ e em 2002 sua participação foi de $22,7 \%$ do rendimento total e originou $25,1 \%$ do índice de Gini. De 1999 a 2002, as aposentadorias e pensões na área rural em 7,6\% a sua participação no índice de Gini para a área rural, quando esse valor para o Brasil foi de $0,8 \%$. As razões de concentração para os três anos analisados são maiores do que o índice de Gini, indicando que as aposentadorias e pensões contribuem para a concentração de renda no meio rural do Brasil.

No espaço rural do Brasil, identifica-se mais fortemente a participação das aposentadorias e pensões no rendimento total per capita dos domicílios. O valor das aposentadoria e pensões foi, em média, de 20,6\% no triênio estudado, ao passo que para o Brasil, foi de $18,3 \%$. Ademais, a taxa de crescimento da participação desse componente no rendimento total foi de $30,46 \%$ de 1999 a 2002 no setor rural, enquanto no Brasil como um todo esse incremento foi de $5,06 \%$.

A tabela 13 mostra a decomposição do rendimento domiciliar per capita para a Região Sul. O rendimento do trabalho principal e as doações têm razão de concentração menor do que o índice de Gini global para os três anos analisados, e que, em 2002, a parcela "juros, etc.". também apresenta menor razão de concentração. Evidencia-se que os rendimentos do trabalho principal têm a maior participação no rendimento total e originam a maior parcela do índice de Gini.

Tabela 12. Decomposição do índice de Gini do rendimento domiciliar per capita no Brasil rural, em 1999, 2001 e 2002: participação do componente no rendimento total $\left(\phi_{h}\right)$, razão de concentração $\left(C_{h}\right)$ e parcela do componente no índice de $\operatorname{Gini} \operatorname{geral}\left(\phi_{h} C_{h}\right)$.

\begin{tabular}{c|c|c|c|c|c|c|c|c|c}
\hline \multirow{2}{*}{$\begin{array}{c}\text { Componente } \\
\text { do } \\
\text { rendimento }\end{array}$} & \multicolumn{10}{|c}{ Brasil Rural } \\
\cline { 2 - 11 } & 1999 & 2001 & 2002 & 1999 & 2001 & 2002 & 1999 & 2001 & 2002 \\
\hline $\begin{array}{c}\text { Trabalho } \\
\text { Principal }\end{array}$ & 75,4 & 70,3 & 69,4 & 0,535 & 0,529 & 0,501 & 0,403 & 0,372 & 0,348 \\
$\begin{array}{c}\text { Outros } \\
\text { trabalhos }\end{array}$ & 4,3 & 3,9 & 3,7 & 0,543 & 0,626 & 0,519 & 0,023 & 0,024 & 0,019 \\
Apos. & 17,4 & 21,7 & 22,7 & 0,542 & 0,586 & 0,566 & 0,094 & 0,127 & 0,128 \\
pensões & & & & & & & & \\
Aluguéis & 1,4 & 1,6 & 1,1 & 0,851 & 0,904 & 0,884 & 0,012 & 0,014 & 0,010 \\
Doações & 0,7 & 0,5 & 0,6 & 0,171 & 0,162 & 0,322 & 0,001 & 0,001 & 0,002 \\
Juros,etc & 1,0 & 2,0 & 2,5 & 0,507 & 0,093 & 0,116 & 0,005 & 0,002 & 0,003 \\
Total & 100,0 & 100,0 & 100,0 & 0,538 & 0,541 & 0,510 & 0,538 & 0,541 & 0,510 \\
\hline
\end{tabular}


Ferreira, C. R; Souza, S. C. I.

Tabela 13. Decomposição do índice de Gini do rendimento domiciliar per capita na região sul, em 1999, 2001 e 2002: participação do componente no rendimento total $\left(\phi_{h}\right)$, razão de concentração $\left(C_{h}\right)$ e parcela do componente no índice de Gini geral $\left(\phi_{h} C_{h}\right)$.

\begin{tabular}{|c|c|c|c|c|c|c|c|c|c|}
\hline \multirow{3}{*}{$\begin{array}{c}\text { Componente } \\
\text { do } \\
\text { rendimento }\end{array}$} & \multicolumn{9}{|c|}{ Região Sul } \\
\hline & 1999 & 2001 & 2002 & 1999 & 2001 & 2002 & 1999 & 2001 & 2002 \\
\hline & $\%\left(\phi_{h}\right)$ & $\%\left(\phi_{h}\right)$ & $\%\left(\phi_{h}\right)$ & $C_{h}$ & $C_{h}$ & $C_{h}$ & $\phi_{h} C_{h}$ & $\phi_{h} C_{h}$ & $\phi_{h} C_{h}$ \\
\hline $\begin{array}{l}\text { Trabalho } \\
\text { Principal }\end{array}$ & 75,6 & 73,5 & 73,8 & 0,539 & 0,519 & 0,505 & 0,407 & 0,382 & 0,372 \\
\hline $\begin{array}{l}\text { Outros } \\
\text { trabalhos }\end{array}$ & 3,5 & 3,5 & 3,3 & 0,793 & 0,791 & 0,747 & 0,027 & 0,028 & 0,025 \\
\hline $\begin{array}{l}\text { Apos. e } \\
\text { pensões }\end{array}$ & 16,8 & 18,8 & 19,1 & 0,568 & 0,570 & 0,549 & 0,095 & 0,107 & 0,105 \\
\hline Aluguéis & 2,5 & 2,4 & 2,3 & 0,791 & 0,776 & 0,779 & 0,019 & 0,019 & 0,018 \\
\hline Doações & 0,6 & 0,5 & 0,6 & 0,426 & 0,455 & 0,505 & 0,003 & 0,002 & 0,003 \\
\hline Juros, etc & 1,0 & 1,2 & 1,0 & 0,683 & 0,623 & 0,435 & 0,007 & 0,008 & 0,004 \\
\hline Total & 100,0 & 100,0 & 100,0 & 0,560 & 0,545 & 0,527 & 0,560 & 0,545 & 0,527 \\
\hline
\end{tabular}

Fonte: Elaboração própria a partir de PNAD (1999, 2001 e 2002)

Com relação à participação do rendimento das aposentadorias e pensões no rendimento total, no período analisado, houve um crescimento de $2,3 \%$. A participação desse componente no índice de Gini total também cresceu $2,9 \%$, enquanto esse índice mostra um crescimento de $0,8 \%$ para o Brasil em seu conjunto.
Nas áreas urbanas da Região Sul, conforme se pode ver na tabela 5, as razões de concentração das aposentadorias e pensões de 2001 e 2002 são superiores ao índice de Gini global. Vê-se que houve um aumento de 2,5\% na participação desse rendimento no total, e de 3,0\% na formação do índice de Gini.

Tabela 14. Decomposição do índice de Gini do rendimento domiciliar per capita na região sul urbano, em 1999, 2001 e 2002: participação do componente no rendimento total $\left(\phi_{h}\right)$, razão de concentração $\left(C_{h}\right)$ e parcela do componente no índice de Gini geral $\left(\phi_{h} C_{h}\right)$.

\begin{tabular}{c|c|c|c|c|c|c|c|c|c}
\hline \multirow{2}{*}{$\begin{array}{c}\text { Componente } \\
\text { do } \\
\text { rendimento }\end{array}$} & \multicolumn{9}{|c}{ Região Sul urbano } \\
\cline { 2 - 10 } & 1999 & 2001 & 2002 & 1999 & 2001 & 2002 & 1999 & 2001 & 2002 \\
\hline $\begin{array}{c}\text { Trabalho } \\
\text { Principal }\end{array}$ & 76,0 & 74,2 & 73,7 & 0,524 & 0,498 & 0,483 & 0,398 & 0,370 & 0,356 \\
$\begin{array}{c}\text { Outros } \\
\text { trabalhos }\end{array}$ & 3,7 & 3,4 & 3,6 & 0,806 & 0,792 & 0,772 & 0,029 & 0,027 & 0,028 \\
Apos. e & 16,4 & 18,2 & 18,9 & 0,526 & 0,541 & 0,506 & 0,086 & 0,099 & 0,096 \\
pensões & & & & & & & & \\
Aluguéis & 2,4 & 2,6 & 2,4 & 0,744 & 0,770 & 0,773 & 0,018 & 0,020 & 0,019 \\
Doações & 0,6 & 0,6 & 0,6 & 0,272 & 0,389 & 0,505 & 0,002 & 0,002 & 0,003 \\
Juros,etc & 0,8 & 1,0 & 0,8 & 0,630 & 0,514 & 0,386 & 0,005 & 0,005 & 0,003 \\
Total & 100,0 & 100,0 & 100,0 & 0,539 & 0,523 & 0,504 & 0,539 & 0,523 & 0,504 \\
\hline
\end{tabular}

Fonte: Elaboração própria a partir de PNAD (1999, 2001 e 2002)

Na Região Sul, as razões de concentração de aposentadorias e pensões são, nos três anos analisados, superiores aos índice de Gini global porém, nas suas áreas rurais (tabela 15), elas são inferiores aos respectivos índices de Gini global, para os anos de 1999 e 2001. Observa-se que houve um crescimento de $2,6 \%$ na participação da renda total e 4,3\% na formação do índice de Gini. 
Tabela 15. Decomposição do índice de Gini do rendimento domiciliar per capita na região sul rural, em 1999, 2001 e 2002 : participação do componente no rendimento total $\left(\phi_{h}\right)$, razão de concentração $\left(C_{h}\right)$ e parcela do componente no índice de Gini geral $\left(\phi_{h} C_{h}\right)$.

\begin{tabular}{c|c|c|c|c|c|c|c|c|c}
\hline \multirow{2}{*}{$\begin{array}{c}\text { Componente } \\
\text { do } \\
\text { rendimento }\end{array}$} & \multicolumn{10}{|c}{ Região Sul rural } \\
\cline { 2 - 10 } & 1999 & 2001 & 2002 & 1999 & 2001 & 2002 & 1999 & 2001 & 2002 \\
\hline $\begin{array}{c}\text { Trabalho } \\
\text { Principal }\end{array}$ & 78,5 & 73,1 & 74,9 & 0,492 & 0,490 & 0,461 & 0,386 & 0,358 & 0,345 \\
$\begin{array}{c}\text { Outros } \\
\text { trabalhos }\end{array}$ & 3,4 & 3,5 & 3,4 & 0,681 & 0,683 & 0,576 & 0,023 & 0,024 & 0,019 \\
Apos. e & 15,4 & 19,9 & 18,0 & 0,441 & 0,490 & 0,472 & 0,068 & 0,098 & 0,085 \\
pensões & 1,4 & 1,7 & 1,9 & 0,676 & 0,772 & 0,802 & 0,010 & 0,013 & 0,015 \\
Aluguéis & 1,4 & & & & & & \\
Doações & 0,4 & 0,3 & 0,1 & 0,604 & 0,506 & 0,143 & 0,002 & 0,001 & 0,001 \\
Juros,etc & 0,9 & 1,5 & 1,8 & 0,498 & 0,452 & 0,325 & 0,004 & 0,007 & 0,005 \\
Total & 100,0 & 100,0 & 100,0 & 0,494 & 0,501 & 0,470 & 0,494 & 0,501 & 0,470 \\
\hline
\end{tabular}

Fonte: Elaboração própria a partir de PNAD (1999, 2001 e 2002)

A tabela 16 mostra a decomposição do rendimento domiciliar per capita para o Estado do Paraná. Verifica-se que o rendimento do trabalho principal participa com o maior percentual do rendimento total, dando origem às maiores parcelas do índice de Gini. Essa mesma tendência pode ser observada para o Paraná rural (tabela 17) e Paraná urbano (tabela 18).
Os dados indicam, entretanto, uma queda na participação percentual dos rendimentos do trabalho principal e um aumento na participação percentual do rendimento das aposentadorias e pensões entre 1999 e 2002, evento que ocorre de forma mais intensa no Estado do Paraná do que no Brasil como um todo.

Tabela 16. Decomposição do índice de Gini do rendimento domiciliar per capita no Estado do Paraná, em 1999, 2001 e 2002: participação do componente no rendimento total $\left(\phi_{h}\right)$, razão de concentração $\left(C_{h}\right)$ e parcela do componente no índice de Gini geral $\left(\phi_{h} C_{h}\right)$.

\begin{tabular}{c|c|c|c|c|c|c|c|c|c}
\hline \multirow{2}{*}{$\begin{array}{c}\text { Componente } \\
\text { do } \\
\text { rendimento }\end{array}$} & \multicolumn{10}{|c}{ Paraná } \\
\cline { 2 - 10 } & 1999 & 2001 & 2002 & 1999 & 2001 & 2002 & 1999 & 2001 & 2002 \\
\hline $\begin{array}{c}\text { Trabalho } \\
\text { Principal }\end{array}$ & 78,2 & $\left.76, \phi_{h}\right)$ & $\%\left(\phi_{h}\right)$ & $C_{h}$ & $C_{h}$ & $C_{h}$ & $\phi_{h} C_{h}$ & $\phi_{h} C_{h}$ & $\phi_{h} C_{h}$ \\
$\begin{array}{c}\text { Outros } \\
\text { trabalhos }\end{array}$ & 3,6 & 7,1 & 3,0 & 0,831 & 0,829 & 0,731 & 0,030 & 0,034 & 0,022 \\
Apos. e & 13,5 & 15,7 & 16,2 & 0,544 & 0,546 & 0,546 & 0,073 & 0,086 & 0,089 \\
pensões & & & & & & & & & \\
Aluguéis & 3,1 & 2,3 & 2,7 & 0,822 & 0,740 & 0,772 & 0,025 & 0,017 & 0,021 \\
Doações & 0,6 & 0,5 & 0,7 & 0,436 & 0,408 & 0,544 & 0,027 & 0,002 & 0,004 \\
Juros,etc & 1,0 & 1,4 & 1,1 & 0,691 & 0,649 & 0,506 & 0,007 & 0,009 & 0,006 \\
Total & 100,0 & 100,0 & 100,0 & 0,576 & 0,563 & 0,536 & 0,576 & 0,563 & 0,536 \\
\hline
\end{tabular}

Fonte: Elaboração própria a partir de PNAD (1999, 2001 e 2002). 
Entre os demais componentes do rendimento, as aposentadorias e pensões são relevantes na participação do rendimento total e na origem do índice de Gini, para o Paraná, Paraná rural e Paraná urbano.

No Paraná urbano, a razão de concentração dos três anos analisados são inferiores ao índice de Gini. Na região Sul urbana e no Brasil urbano, a razão de concentração é superior ao índice de Gini, com exceção de 1999 para a região sul urbana.

Para o Paraná, somente em 2002 a razão de concentração é superior ao índice de Gini global, enquanto na região Sul e Brasil, aqueles indicadores são superiores ao Gini global nos três anos analisados.

A participação do rendimento de aposentadorias e pensões no rendimento total, para o Paraná rural cresceu $2,8 \%$, assim como a da região sul foi de $2,6 \%$. Se comparadas às do Brasil rural (5,3\%), elas se mostram inferiores, apesar disso, essa participação é significativa. Em 2001, a parcela do rendimento de aposentadorias e pensões rural foi superior ao Paraná e ao Paraná urbano, enquanto em 2002 essa parcela foi superior ao Paraná urbano.

Tabela 17. Decomposição do índice de Gini do rendimento domiciliar per capita no Estado do Paraná urbano, em 1999, 2001 e 2002: participação do componente no rendimento total $\left(\phi_{h}\right)$, razão de concentração $\left(C_{h}\right)$ e parcela do componente no índice de $\operatorname{Gini}$ geral $\left(\phi_{h} C_{h}\right)$.

\begin{tabular}{c|c|c|c|c|c|c|c|c|c}
\hline \multirow{2}{*}{$\begin{array}{c}\text { Componente } \\
\text { do } \\
\text { rendimento }\end{array}$} & \multicolumn{10}{|c}{ Paraná urbano } \\
\cline { 2 - 10 } & 1999 & 2001 & 2002 & 1999 & 2001 & 2002 & 1999 & 2001 & 2002 \\
\hline $\begin{array}{c}\text { Trabalho } \\
\text { Principal }\end{array}$ & 78,5 & 77,3 & 76,4 & 0,551 & 0,531 & 0,503 & 0,433 & 0,410 & 0,384 \\
$\begin{array}{c}\text { Outros } \\
\text { trabalhos }\end{array}$ & 4,0 & 4,1 & 3,3 & 0,854 & 0,832 & 0,796 & 0,034 & 0,033 & 0,027 \\
Apos. e & 13,0 & 14,4 & 15,2 & 0,468 & 0,467 & 0,456 & 0,061 & 0,067 & 0,069 \\
pensões & & & & & & & \\
Aluguéis & 2,9 & 2,4 & 3,2 & 0,799 & 0,724 & 0,794 & 0,023 & 0,018 & 0,026 \\
Doações & 0,7 & 0,7 & 0,8 & 0,331 & 0,361 & 0,545 & 0,002 & 0,003 & 0,005 \\
Juros,etc & 0,9 & 1,0 & 1,0 & 0,605 & 0,420 & 0,417 & 0,005 & 0,004 & 0,004 \\
Total & 100,0 & 100,0 & 100,0 & 0,559 & 0,536 & 0,515 & 0,559 & 0,536 & 0,515 \\
\hline
\end{tabular}

Fonte: Elaboração própria a partir de PNAD (1999, 2001 e 2002)

A crescente relevância dos benefícios previdenciários rurais é um dos elementos que indicam semelhanças aos mais diversos países, e segundo Schwarzer (2000), deverá aprofundar-se em decorrência do processo de envelhecimento da população e da restrição dos mercados de trabalho, particularmente do trabalho rural. 
Tabela 18. Decomposição do índice de Gini do rendimento domiciliar per capita no Estado do Paraná rural, em 1999, 2001 e 2002 : participação do componente no rendimento total $\left(\phi_{h}\right)$, razão de concentração $\left(C_{h}\right)$ e parcela do componente no índice de Gini geral $\left(\phi_{h} C_{h}\right)$.

\begin{tabular}{c|c|c|c|c|c|c|c|c|c}
\hline \multirow{2}{*}{$\begin{array}{c}\text { Componente } \\
\text { do } \\
\text { rendimento }\end{array}$} & \multicolumn{10}{|c}{ Paraná rural } \\
\cline { 2 - 10 } & 1999 & 2001 & 2002 & 1999 & 2001 & 2002 & 1999 & 2001 & 2002 \\
\hline $\begin{array}{c}\text { Trabalho } \\
\text { Principal }\end{array}$ & 80,8 & 75,1 & 78,2 & 0,496 & 0,564 & 0,504 & 0,400 & 0,423 & 0,394 \\
$\begin{array}{c}\text { Outros } \\
\text { trabalhos }\end{array}$ & 3,7 & 3,9 & 4,1 & 0,720 & 0,750 & 0,551 & 0,027 & 0,030 & 0,023 \\
Apos. e & 12,6 & 16,8 & 15,4 & 0,440 & 0,522 & 0,551 & 0,055 & 0,088 & 0,085 \\
pensões & 1,9 & 1,8 & 0,7 & 0,738 & 0,790 & 0,539 & 0,014 & 0,014 & 0,004 \\
Aluguéis & 0,2 & 0,4 & 0,1 & 0,179 & 0,633 & 0,556 & 0,001 & 0,002 & 0,001 \\
Doações & 0,2 & 2,0 & 1,4 & 0,505 & 0,614 & 0,438 & 0,004 & 0,012 & 0,006 \\
Juros,etc & 0,8 & & & & & & \\
Total & 100,0 & 100,0 & 100,0 & 0,501 & 0,569 & 0,513 & 0,501 & 0,569 & 0,513 \\
\hline
\end{tabular}

Fonte: Elaboração própria a partir de PNAD (1999, 2001 e 2002)

No Paraná rural, a razão de concentração é superior ao índice de Gini global somente em 2002, coincidindo com o comportamento da região Sul rural, enquanto no Brasil rural esse índice é superior ao índice de Gini global, nos três anos analisados.

Um indicador interessante para o Paraná e Paraná rural, que coincide com o comportamento do setor rural da Região Sul, é que o componente trabalho principal não tem colaborado para a concentração de renda, ou seja, a razão de concentração é menor do que o índice de Gini, mas as aposentadorias e pensões invertem seus papeis de concentradoras de renda nos anos 1999 e 2001.

A participação das aposentadorias e pensões na formação do índice de Gini para o Paraná, Paraná urbano e Paraná rural cresceu no período analisado. Salienta-se, que no Paraná rural, o crescimento foi de 5,6\%, entre 1999 e 2002. Esse crescimento ficou acima das avaliações feitas para o Paraná e Paraná urbano, que tiveram um crescimento de 3,9\% e 2,5\%, respectivamente. Esse percentual de crescimento das aposentadorias e pensões na participação do índice de Gini para o Paraná rural também é superior à participação do Brasil $(0,8 \%)$, Brasil urbano $(0,9 \%)$, Sul (2,9\%), Sul urbano $(3,0 \%)$ e Sul rural $(4,3 \%)$, sendo superado apenas pelo Brasil rural, que cresceu $7,6 \%$.

\section{Considerações Finais}

A distribuição do rendimento domiciliar per capita em 11 estratos mostrou que no Brasil como um todo e no meio urbano, em particular, o maior percentual de domicílios e de pessoas recebe até um salário mínimo e meio, e, portanto, fazem parte dos relativamente pobres. Por outro lado, o maior percentual do rendimento total e do rendimento de aposentadorias e pensões está concentrado nos estratos superiores, nos quais estão localizados os relativamente ricos. No meio rural, verificou-se que o maior percentual de domicílios e de pessoas também recebe até um salário mínimo e meio, mas ficam com os maiores percentuais do rendimento total e do rendimento domiciliar de aposentadorias e pensões.

A decomposição do rendimento domiciliar per capita nos seus vários componentes, permite avaliar a magnitude da sua contribuição para a desigualdade no país, e, por meio dela verifica-se que é crescente o percentual de rendimento domiciliar médio no Brasil advindo das aposentadorias e pensões. Em 1999, o rendimento das aposentadorias e pensões participava com $17,8 \%$ da renda total, e, em 2002, esse valor foi de $18,7 \%$. Os resultados obtidos para o Paraná indicam, nos anos selecionados, que as aposentadorias e pensões são uma das duas parcelas mais 
significativas no rendimento domiciliar e, seguindo a tendência brasileira, mas em ritmo intensificado, esse componente tem elevado sua participação na renda. Se, para o Brasil, os dados apontam 0,9\% de crescimento, para a Região Sul é de $2,3 \%$ e para o Paraná foi de $2,7 \%$.

No tocante ao rendimento domiciliar per capita, no Brasil rural verifica-se que a participação do rendimento das aposentadorias e pensões no rendimento total é ainda mais acentuado, crescendo $5,3 \%$. Na Região Sul, esse crescimento foi de 2,6\% e no Paraná rural de 2,8\%. Esse crescimento na parcela de rendimento das aposentadorias e pensões é bem vindo ao setor rural, que, de forma geral, é carente de recursos.

No espaço rural, a razão de concentração para o Brasil rural, no período analisado, é maior que o valor do índice de Gini global, e isso indica que, nesse âmbito, há contribuição das aposentadorias para a desigualdade de renda. Já na região sul rural e Paraná rural, a razão de concentração nos anos de 1999 e 2001 indica a não contribuição da parcela para aumentar a desigualdade na região, com exceção do ano de 2002. Por outro lado, a estratificação dos rendimentos domiciliares permitiu verificar que, para todas as regiões rurais analisadas, a concentração dos rendimentos total e de aposentadorias e pensões localiza-se nos estratos inferiores de renda.

\section{Referências}

AMSBERG, J. V.; LANJOUW, P.; NEAD, K. A focalização do gasto social sobre a pobreza no Brasil. In: HENRIQUES, R. (Org.). Desigualdade e pobreza no Brasil. Rio de Janeiro: IPEA, 2000.

BARROS, R. P.; FOGUEL, M. N. Focalização dos gastos públicos sociais e erradicação da pobreza no Brasil. In: HENRIQUES, R. (Org.). Desigualdade e pobreza no Brasil. Rio de Janeiro: IPEA, 2000. cap.25, p.719-739.

BRANT,R .Desenvolvimento social, previdência e pobreza no Brasil. Conjuntura Social, v.12, n.2, p.763, abr./jun.2001.
CAMARANO, A.A.Envelhecimento da população brasileira: uma contribuição demográfica. Rio de Janeiro: IPEA, 26p.(Texto para Discussão,858).

DELGADO, G. C.; CARDOSO JUNIOR, J. C. O idoso e a previdência rural no Brasil: a experiência recente da universalização. In: CAMARANO, A. A. (Org.). Muito além dos 60: os novos idosos brasileiros. Rio de Janeiro: IPEA, 1999. cap.11, p.319-343.

FERREIRA, C. R. Participação das aposentadorias e pensões na desigualdade da distribuição da renda no Brasil no período de 1981 a 2001. 2003.Tese (Doutorado) - Escola Superior de Agricultura "Luiz de Queiroz”, Universidade de São Paulo, Piracicaba.

FERREIRA, C. R.; SOUZA, S. C. I. A contribuição das parcelas do rendimento domiciliar per capita para a desigualdade no Brasil. Londrina: EDUEL, 2004a. (mimeo)

Previdência social e desigualdade: a participação das aposentadorias e pensões na distribuição da renda no Brasil - 1981 a 2001. Londrina: EDUEL, 2004b. (mimeo)

HOFFMANN, R. A Subdeclaração dos rendimentos. São Paulo em Perspectiva, São Paulo, v.2, n.1, p.5054, jan./mar. 1988.

HOFFMANN, R. Desigualdade no Brasil: a contribuição das aposentadorias. Disponivel em: <www.eco.unicamp.br/projetos/rurbano.html>. Acesso em: 17 out. 2002.

INSTITUTO BRASILEIRO DE GEOGRAFIA E ESTATÍSTICA. Pesquisa Nacional por Amostra de Domicílios (compact disc). Rio de Janeiro, 1999.

INSTITUTO BRASILEIRO DE GEOGRAFIA E ESTATÍSTICA. Pesquisa Nacional por Amostra de Domicílios Rio de Janeiro, 2001 . (compact disc). 
INSTITUTO BRASILEIRO DE GEOGRAFIA E ESTATÍSTICA. Pesquisa Nacional por Amostra de Domicílios (compact disc). Rio de Janeiro, 2002. Sintese de indicadores sociais 2003. Disponível em: 〈www.ibge.gov.br〉. Acesso em 13 jul. 2004.

MARIANO, J. L.; LIMA, R. C. A desigualdade da renda rural no Nordeste: análise da desagregação do coeficiente de Gini e da sensibilidade do índice de bem-estar de Sen. Análise Econômica, Porto Alegre, v.16, n.29, p.103-118, mar. 1998.

NAJBERG,S.;IKEDAM,M. Previdência no Brasil: desafios e limites. In:GIAMBIAGI, F.; MOREIRA, M.M. A economia brasileira nos anos 90. Rio de Janeiro:BNDES,1999, cap.3, p.261-290.

NEDER, H. D. Os efeitos das atividades não agrícolas na distribuição de renda no meio rural (compact disc). In: CONGRESSO BRASILEIRO DE ECONOMIA E SOCIOLOGIA RURAL, 39., 2001, Recife. Anais... Brasília: SOBER, 2001.

ORNÉLAS, W. O novo modelo previdenciário brasileiro:uma fase de transição. Disponível em <www.previdenciasocial.gov.br/07_08.htm>. Acesso em 20 mai. 2002.

ORNÉLAS, W. Novo rumo para a previdência brasileira.Disponível em <www.previdenciasocial.gov.br/07_08.htm>. Acesso em 13 jun.. 2002.

PYATT, G.; CHEN, C.; FEI, J. The distribution of income by factor components. The Quarterly Journal of Economics, Cambridge, v.95, n.3, p.451473, nov. 1980.

SCHWARZER, H. Paradigmas de previdência social rural: um panorama da experiência internacional.Brasília:IPEA,2000.
SHORROCKS, A. F. Inequality decomposition by factor components. Econometrica, Chicago,v.50, n.1, p.193-211, jan. 1982.

STEPHANES, R. Reforma da previdência sem segredos. 2. ed. Rio de Janeiro: Record, 1999. 